Www.jmscr.igmpublication.org

Impact Factor 5.244

Index Copernicus Value: 83.27

ISSN (e)-2347-176x ISSN (p) 2455-0450

crossref DOI: https://dx.doi.org/10.18535/jmscr/v4i12.78

Journal Of Medical Science And Clinical Research

\title{
A Study to Find out the Effectiveness of Taping Versus Semi rigid Bracing in Ankle Sprain
}

\author{
Authors \\ R.Sreekar Kumar Reddy ${ }^{1}$, N.Vamsidhar ${ }^{2}$, B.Sivakumar ${ }^{3}$, Dr Biju Ravindran ${ }^{4}$ \\ ${ }^{1}$ Professor, Narayana College of Physiotherapy, Nellore \\ ${ }^{2}$ Assistant Professor, Narayana College of Physiotherapy, Nellore \\ ${ }^{3}$ Assistant Professor, Narayana College of Physiotherapy, Nellore \\ ${ }^{4}$ Head of Department, Department of Orthopaedics, Narayana Medical College and Hospital, Nellore
}

\begin{abstract}
BACKGROUND: Ankle sprain is one of the most common musculoskeletal injuries, accounting for an estimated 600.000 persons per year. Preventive interventions such as taping and bracing are thought to decrease ankle sprain incidence by providing mechanical support and enhanced proprioception may be associated with ankle injury.

METHODS: A total number of 30 subjects were divided into 2 groups as group A and group B, in which each group consists of 15 subjects. The group A subjects will be subjected to ultrasound with taping for a period of five times a week for 3 weeks. The group B subjects will be subjected to splint with ultrasound for a period of five times a week for 3 weeks.

RESULTS: This study shows that there is significant difference at 95\% of Confidence Intervals ( $p=0.41$ i.e.>0.05) by using unpaired 't' test in the effectiveness of Taping with ultrasound Technique versus semi rigid bracing with ultrasound on ankle sprain patients with specific ankle pain.

CONCLUSION: This study shows that treatment of acute lateral ankle sprain with a semi-rigid brace with ultrasound leads to less complications and a higher patient satisfaction than treatment taping with ultrasound.
\end{abstract}

KEYWORDS: Taping, Semi-rigid brace, Ultrasound therapy, Ankle sprain.

\section{INTRODUCTION}

Ankle sprain is one of the most common musculoskeletal injuries, accounting for an estimated 600.000 persons per year. Ankle sprains are one of the most common injuries in sports and occur nearly 7 times more frequently than all other ankle injuries. Fifty percent of these injuries arise in sports and in 75 percent the cause is an inversion trauma. In the India ankle sprains occur in an estimated 23.000 people per day which equals about 8.4 million people per year.
Functional treatment is a commonly accepted treatment of ankle sprains. Functional treatment includes a wide variety of options. The most common functional treatment methods are taping or bracing which have superior functional results compare to plaster immobilization and elastic bandage.

Patients were included if they sustained a grade 2 or 3ankle sprain. Grade 1 ankle sprain was determined as the absence of a hematoma and tenderness at the anterior lateral ligament. Patients 
with the presence of a lateral hematoma and tenderness at the anterior lateral ligament without instability. The specificity and sensitivity of delayed physical examination for the presence of absence of a lateral ankle ligament rupture are 84 percent and $96 \%$ respectively.

A positive anterior drawer test in combination with pain on palpation on the ATFL and hematoma discoloration has a sensitivity of $100 \%$ and specificity $77 \%$.

In impossible, were mentally disabled or were unwilling to a recent systematic review, the ankle was found to be the most common site of injury in 24 of the 70 sports studied. In addition, $22 \%$ of sports injuries presenting to emergency rooms were ankle injuries, among which sprain was the most common injury followed by fracture (the ratio of sprain to fracture is 8:1)Lateral ankle sprains account for $85 \%$ of all ankle sprains, the most common mechanism of injury being inversion of the plantar-flexed foot.

Similarly, after ankle fracture, symptoms such as pain, joint stiffness, and limitation in lower limb activities occur and may persist into the long term. The type of functional support that is preferable to use may depend on the main outcome desired. A systematic review comparing the use of one type of functional support with another (included elastic bandage, tape, semi-rigid support, and laceup ankle support) found them equally effective in reducing pain, swelling, ankle instability, and preventing recurrent sprain.

A semi-rigid support appeared more effective for earlier return to sport, and tape resulted in more skin complications. A more recent comparison of an Aircast ankle brace with elastic support bandage group demonstrated a significant improvement in ankle joint function at 10 and 30 days when using the ankle brace.

Preventive interventions such as taping and bracing are thought to decrease ankle sprain incidence by providing mechanical support and enhanced proprioception to the which may be associated with ankle injury, on factors such as range-of-motion restriction and functional performance, few author have evaluated the effect of preventive measures on reducing the incidence of ankle sprains.

\section{METHODOLOGY}

Subjects were selected through simple Random Sampling. The purpose of this study was explained to all the subjects. An informed consent was taken, followed by demographic data from each subjects. The study included a sample of 30 subjects from Outpatient Physiotherapy department of Narayana Medical Institutions, Nellore.

Patients were included if they sustained a grade I or II ankle sprain (significant damage to lateral ligaments defined by the presence of a lateral hematoma and tenderness at the anterior lateral ligament without (grade I) or with anterior drawer instability (grade II) as assessed by a supervised resident or by the treating physician when presented in the outpatient clinic within 5-7 days. Grade I ankle sprain was determined as the absence of a hematoma and tenderness at the anterior lateral ligament. Patients with the presence of a lateral hematoma and tenderness at the anterior lateral ligament without instability were defined as grade I) as patient with lateral hematoma, tenderness and instability were defined as grade II. Subjects were excluded patients undergoing preventive treatment of recurrent ankle sprains. Patients were excluded if they had a fracture, if their age was under 16 or over 55 years; if they had experienced a previous ankle sprain or fracture; if they sustained swelling that made treatment with tape impossible, were mentally disabled or were unwilling to participate in the study.

A total number of 30 subjects diagnosed with ankle sprain over lateral collateral ligament will be selected based on inclusion and exclusion criteria. After the informed consents obtained, they will be divided into 2 groups as group A and group $\mathrm{B}$, in which each group consists of 15 subjects.

Prior to the treatment pre test will be conducted for the group A and group B to check the ankle 


\section{JMSCR Vol||04||Issue||12||Page 14792-14798||December}

range of motion with karlsson scoring scale and the results will be recorded.

After a brief demonstration about taping with ultrasound, the group A subjects will be subjected to ultrasound with taping for a period of five times a week for 3 weeks.

A brief demonstration about splint with ultrasound is given to the group B subjects and the group B subjects will be subjected to splint with ultrasound for a period of five times a week for 3 weeks.
The post test will be conducted for group A and group B on karlsson scoring scale and the results will be recorded and analysed to compare the pre test and post test results.

\section{DATA ANALYSIS}

The data were analysed by repeated measures Unpaired ' $t$ ' test at 0.41 level of significance and using SOSS version.

\section{INDEPENDENT SAMPLE T-TEST}

\section{Group Statistics}

\begin{tabular}{|l|c|c|c|c|c|}
\hline & Tech & $\mathrm{N}$ & Mean & Std. Deviation & P-VALUE \\
\hline \multirow{3}{*}{ Age } & 1.00 & 15 & 27.5333 & 4.54920 & 0.419 \\
& 2.00 & 15 & 26.2667 & 3.88158 & \\
Pre VAS & 1.00 & 15 & 7.3333 & .48795 & 0.028 \\
& 2.00 & 15 & 7.7333 & .45774 & \\
Post VAS & 1.00 & 15 & 1.8000 & .67612 & \\
& 2.00 & 1 & & & \\
& & 5 & 3.6667 & .61721 & \\
Pre Karlsson & 1.00 & 15 & 75.3333 & 4.80575 & 0.0001 \\
& 2.00 & 15 & 79.6667 & 5.16398 & \\
& 1.00 & 15 & 30.1333 & 3.73911 & $<0.0001$ \\
\hline
\end{tabular}

Group Statistics

\begin{tabular}{|l|l|l|l|c|c|}
\hline & Tech & N & Mean & Std. Deviation & P-VALUE \\
\hline \multirow{3}{*}{ Pre VAS } & 1.00 & 15 & 7.3333 & .48795 & 0.028 \\
& 2.00 & 15 & 7.7333 & .45774 & \\
Post VAS & 1.00 & 15 & 1.8000 & .67612 & $<0.0001$ \\
& 2.00 & 15 & 3.6667 & .61721 & \\
\hline
\end{tabular}

Group Statistics

\begin{tabular}{|ll|l|l|l|l|}
\hline & Tech & N & Mean & Std. Deviation & P-VALUE \\
\hline \multirow{3}{*}{ Pre Karlsson } & 1.00 & 15 & 75.3333 & 4.80575 & 0.024 \\
& 2.00 & 15 & 79.6667 & 5.16398 & \\
Post Karlsson & 1.00 & 15 & 30.1333 & 3.73911 & \multirow{2}{*}{0.0001} \\
& 2.00 & 15 & 45.6667 & 2.60951 & \\
\hline
\end{tabular}



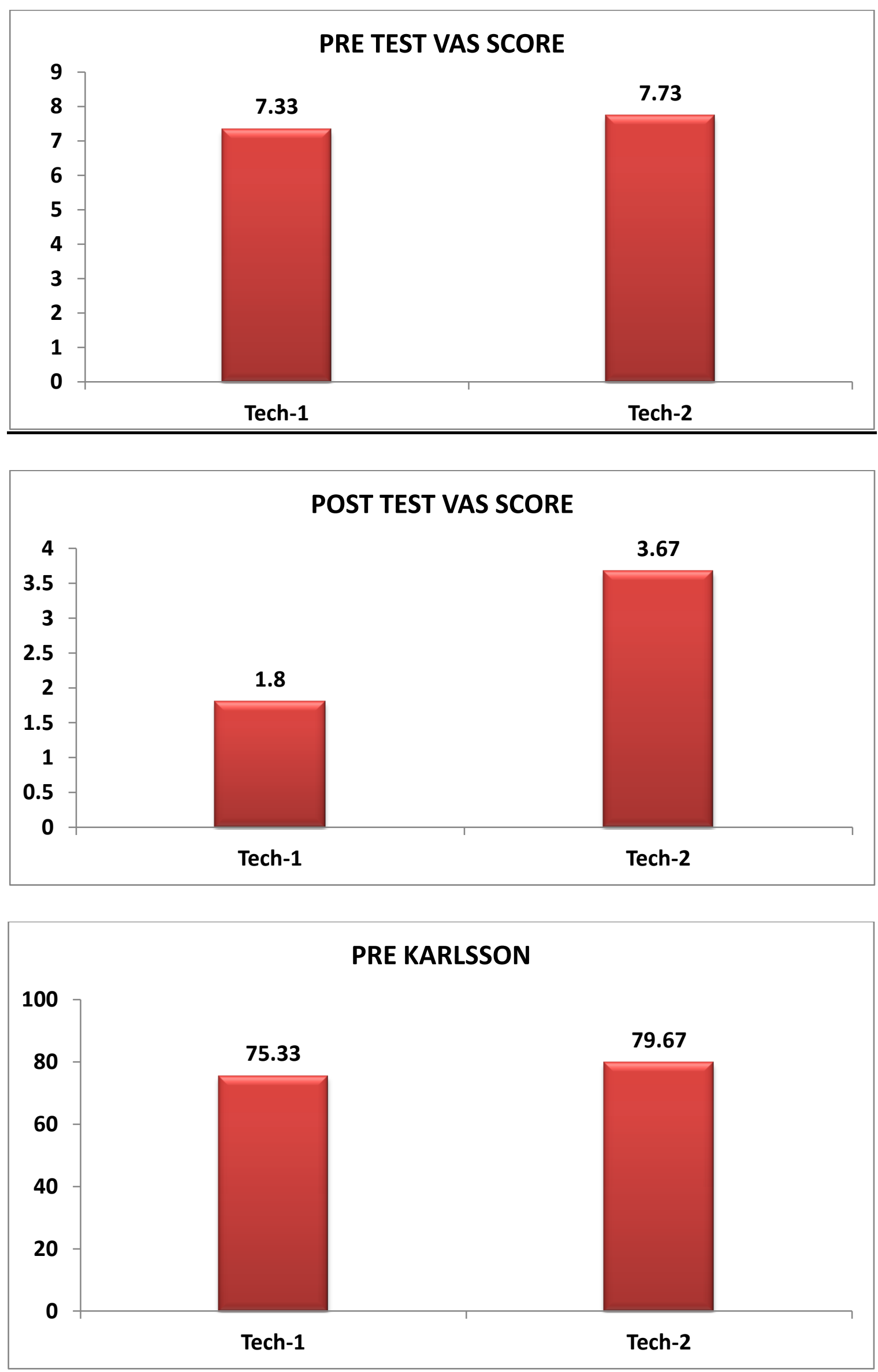
Group Statistics

\begin{tabular}{|l|c|c|c|c|c|}
\hline & Tech & $\mathrm{N}$ & Mean & Std. Deviation & P-VALUE \\
\hline \multirow{2}{*}{ Pre Karlsson } & 1.00 & 15 & 75.3333 & 4.80575 & 0.024 \\
& 2.00 & 15 & 79.6667 & 5.16398 & \\
Post Karlsson & 1.00 & 15 & 30.1333 & 3.73911 & $<0.0001$ \\
& 2.00 & 15 & 45.6667 & 2.60951 & \\
\hline
\end{tabular}

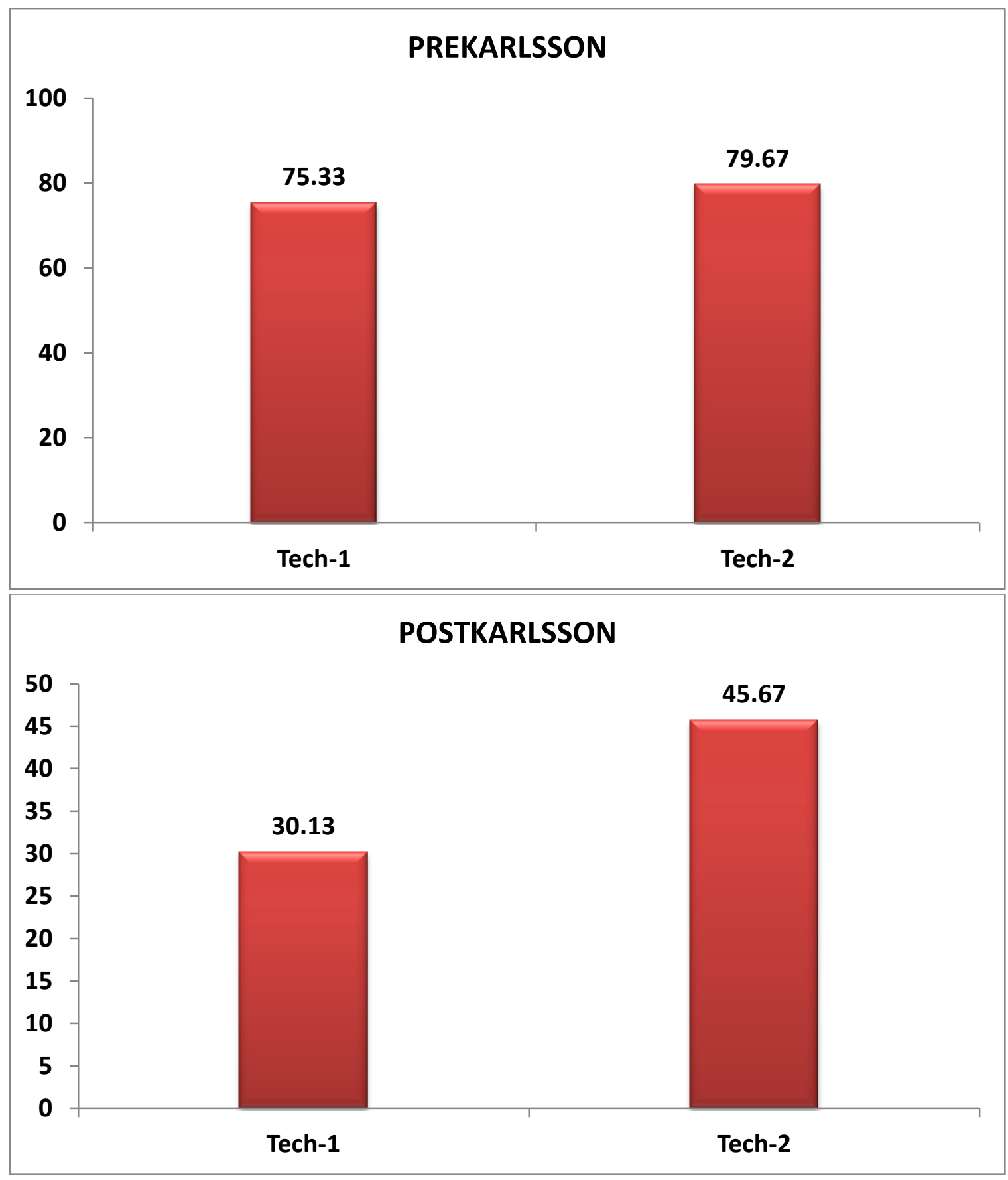




\section{RESULTS}

The Pre and Post Taping with ultrasound technique on ankle sprain shows significant difference $(\mathrm{p}<0.0001)$ by using unpaired ' $\mathrm{t}$ ' test in relieving non specific ankle sprain.

The Pre and Post semi rigid bracing with ultrasound technique on ankle sprain shows significant difference $(\mathrm{p}<0.0001)$ using UN Paired' $t$ ' test in relieving non specific ankle sprain.

This study shows that there is significant difference at $95 \%$ of Confidence Intervals $(\mathrm{p}=0.41$ i.e.>0.05) by using unpaired ' $t$ ' test in the effectiveness of Taping with ultrasound Technique versus semi rigid bracing with ultrasound on ankle sprain patients with specific ankle pain.

\section{DISCUSSION}

The purpose of this study was to find out the effect of Taping with ultrasound versus semi rigid bracing with ultrasound on ankle sprain patients.

30 subjects were selected who fulfilled the predetermined inclusive and exclusive criteria. The subjects were divided into two groups, 15 in each group. Group A underwent Taping with ultrasound and Group B semi rigid bracing with ultrasound.

The results indicated that the effectiveness of taping versus semi rigid bracing has shown significant difference at $95 \%$ of $\mathrm{CI}(\mathrm{P}>0.05)$ in relieving of ankle pain.

In both groups group $\mathrm{B}$ shows significant improvement in pain and functional outcome score with karlsson.

Whereas group A and B with in group A itself compare to with pre and post improvement shown ,group B itself comparative with pre and post improvement shown, where as comparison between group A and group B, group B shown significant difference.

Functional treatment is a widely used and generally accepted treatment for ankle sprain. A number of studies assessing the effectiveness of different conservative treatments of acute ankle sprain have been performed, but until now, little was known about patient satisfaction in relation to the functional outcome. The results of these randomized controlled trail comparing semi rigid ankle brace with tape treatment demonstrated improved patient satisfaction with less local complications in patients treated with a semi rigid brace, but overall showed no improved functional outcome.

(Kerkhoffs GM et al,2002) ${ }^{\mathbf{5}}$ reviewed different functional treatment strategies for acute lateral ankle ligament injuries in adults in a meta analysis. Although it was impossible to make definitive conclusions about the most effective functional treatment because diversity of outcome results prohibited pooling of results, there seemed to be no evidence that using a semi rigid brace is superior to taping concerning functional outcome in the individual studies.

A semi rigid ankle support provided more stability and quicker return to work and sport than an elastic bandage in addition as for the functional outcome objective (ROM) as well as patient reported functional outcome score (karlsson scale) this study shows that there was no difference functional ability between the 2 groups. In addition the pain score was similar between the tape and semi rigid brace treatment at 3 months.

In addition, the costs of treatment with a semirigid brace are higher than the treatment with a tape described the effectiveness and costs in relation to the patient satisfaction in a small study on the treatment of acute ankle sprain with tape and treatment with a brace and found higher patient satisfaction, but also higher costs of the treatment with a semi-rigid brace ( $€ 183$ versus $€ 238)$ Specification of the costs are illustrated in the article by Diercks.

This comparison seems to be different when tape and brace interventions are used as a preventive measure. In a study by Olmsted et al. found that the costs of preventing one ankle sprain was significantly higher using preventive tape treatment compared to preventive brace treatment. 


\section{CONCLUSION}

This study shows that treatment of acute lateral ankle sprain with a semi-rigid brace with ultrasound leads to less complications and a higher patient satisfaction than treatment taping with ultrasound.

In line with previous studies there is no difference regarding functional outcome and pain. Therefore using a semi-rigid brace should be considered for treatment of acute ankle sprains.

Our first conclusion is that taping and bracing appear to be more effective in preventing ankle sprains in with a history of ankle sprain than in those without a history of ankle sprain.

Second, when deciding whether should be taped or braced, the increased cost and time of ankle taping, compared with bracing. must be considered.

Ankle bracing, therefore, may be a better way to provide the support necessary to prevent ankle sprains.

\section{REFERENCES}

1. Kannus P, Renstrom P: Treatment for acute tears of the lateral ligaments of the ankle: operation, cast or early controlled mobilization. J Bone Joint Surg [Am] 1991, 73:305-312.

2. J Athl Train 2004, 39(1):95-100. Boyce SH, Quigley MA. Review of sports injuries presenting to an accident and emergency department. Emerg Med J. 2004 Nov;21(6):704-706.

3. Kerkhoffs GM, Rowe BH, Assendelft WJ, Kelly K, Struijs PA, van Dijk CN: Immobilisation and functional treatment for acute lateral ankle ligament injuries in adults. Cochrane Database Syst Rev 2002, (3):CD003762.

4. Karlsson J, Eriksson BI, Swärd L. Early functional treatment for acute ligament injuries of the ankle joint. Scand J Med Sci Sports. 1996 Dec;6(6):341-345
5. Jongen SJM, Pot JH, Dunki Jacobs PB:

Treatment of the sprained ankle. Geneesk Sport 1992, 25:98-101.

6. Lin CW, Hiller CE, de Bie RA: Evidencebased treatment for ankle injuries: a clinical perspective.

7. J Man Manip Ther 2010 Mar, 18(1):22-28 Kemler E, van de Port I, Backx F, van Dijk CN: A systematic review on the treatment of acute ankle sprain: brace versus other functional treatment types. Sports Med 2011 Mar 1, 41(3):185-197

8. Dettori JR, Pearson BD, Basmania CJ, Lednar WM. Early ankle mobilization, Part I: The immediate effect on acute, lateral ankle sprains (a randomized clinical trial). Mil Med. 1994 Jan;159(1):15-20]

9. Robroek WCL, van de Beek G: Bandages and bandaging techniques Skills in medicine. UItgeverij Skillslab, Institute for Medical Education, Maastricht University; 2009.

10. Karlsson J, Peterson L: Evaluation of ankle joint function: the use of a scoring scale. Foot 1991, 1:15-1923. OgilvieHarris DJ, Gilbart M. Treatment modalities for soft tissue injuries of the ankle: a critical review. Clin J Sport Med. 1995 Jul;5(3):175-186.

11. Boyce SH, Quigley MA, Campbell S: Management of ankle sprains: a randomised controlled trial of the treatment of inversion injuries using an elastic support bandage or an Aircast ankle brace. Br J Sports Med 2005, 39:91.

12. Leanderson J, Wredmark T. Treatment of acute ankle sprain. Comparison of a semirigid ankle brace and compression bandage in 73 patients. Acta Orthop Scand. 1995 Dec;66(6):529-531

13. Callaghan MJ. Role of ankle taping and bracing in the athlete. Br J Sports Med. 1997 Jun;31(2):102-108. 